\title{
Immunochemical Relationship between Streptococcus MG, F III and Streptococcus salivarius
}

\author{
By J. M. N. WILLERS, H. OTTENS AND M. F. MICHEL \\ Laboratory of Microbiology, State University, Utrecht; Research Department \\ of the Royal Dutch Fermentation Industry, Delft and Laboratory of Micro- \\ biology, State University, Utrecht, The Netherlands
}

(Received 29 July 1964)

\begin{abstract}
SUMMARY
The identity of the polysaccharide antigens of Streptococcus MG and streptococci with group antigen $F$ and type antigen III is shown by precipitation reactions with formamide extracts, cross-absorption tests, sugar composition and by the inhibition of the quantitative precipitation reaction. On this basis Streptococcus MG can be classified as an F III strain.

The relationship between Streptococcus MG and Streptococcus salivarius type I is explained by their common reactions with anti-III serum. Inhibition of the quantitative precipitations with simple sugars suggest that the determinant groups of the type III and the 'salivarius' antigen are not quite identical, although both antigens contain a $\beta$-glucosidic and a galactosidic group.

A second unrelated antigen has been found in some 'salivarius' strains alone (represented by strain 51) or together with type III antigen. The quantitative precipitation of the strain 51/anti-strain 51 system was only slightly inhibited by rhamnose.

The qualitative composition of the sugar components of the formamide extracts of Streptococcus MG, F III, both 'salivarius' types of 0 III are compared.
\end{abstract}

\section{INTRODUCTION}

Mirick, Thomas, Curnen \& Horsfall (1944) isolated from the lungs of a fatal case of primary atypical pneumonia a streptococcus strain which was first designated Streptococcus 344, later on Streptococcus MG. These authors described Streptococcus MG as a separate serological entity (Mirick et al. 1944a) only related to Streptococcus salivarius type I (Mirick et al. 1944 $b$ ) as described by Sherman, Niven \& Smiley (1943). Streptococcus MG gives capsular swelling and agglutination with homologous serum. Precipitation reactions can be done with various kinds of extracts of these streptococci.

Streptococcus MG (NCTC 8037/50) is used in several laboratories as a standard strain in testing for MG antibodies.

Many indifferent (no $\alpha$ - or $\beta$-haemolysis) and haemolytic streptococci isolated from dental root canals contain the group antigen $\mathrm{F}$ and one of the type antigens I-V observed in this group (Ottens \& Winkler, 1962). The serological identification of these strains was based on the precipitin reaction with the soluble polysaccharide antigens obtained by hot formamide extraction of whole cocci. Data about the chemical constitution of these group and type antigens and about the structure of 
the determinant groups of these antigens were described by Willers, Michel, Sijsma \& Winkler (1964).

In the present paper data are given for the identity of the carbohydrate antigens of Streptococcus MG (NCTC 8037/50) and an F strain with type antigen III. Many Streptococcus salivarius strains also contain an antigen reacting with anti-III serum. The serological relationships between these strains and the chemical composition of their antigens are described.

\section{METHODS}

Strains. Streptococcus MG (NCTC 8037/50), Streptococcus salivarius (NCTC 8606) and 16 strains provisionally classified as MG strains were obtained from Dr C. E. de Moor (National Institute of Public Health, Utrecht, The Netherlands). Other streptococci also provisionally classified as MG strains were obtained from Professor Dr M. Seeleman (Institute of Dairying Hygiene, Kiel, Germany). Forty-two S. salivarius strains were isolated from dental plaque material (materia alba).

The qualitative chemical analysis was performed by the method of Michel \& Gooder (1962).

The formamide extraction of the bacteria, the purification of the crude formamide extracts, the isolation of polysaccharides from the medium, the quantitative precipitin inhibition technique and the preparation of sera against group $F$ and against the types I up to $V$ have been described earlier (Willers et al. 1964). Anti-MG serum was obtained from Dr C. E. de Moor. All other anti-group sera were from Burroughs Wellcome. Anti-A variant serum was a generous gift of Mr W. R. Maxted.

Absorption of sera. Heat-killed streptococci were washed twice with saline and finally centrifuged at $36,000 \mathrm{~g}$. Two volumes of serum were mixed with the sedimented bacteria, incubated during $1 \mathrm{hr}$ at $37^{\circ}$ and centrifuged at $36,000 \mathrm{~g}$.

\section{RESULTS}

Serology. Formamide extracts of Streptococcus MG (NCTC 8037/50) gave positive reactions with anti-F and anti-III sera. Polysaccharides isolated from the medium reacted with anti-III serum only.

Anti-MG serum reacted with formamide extracts of the homologous strain and with strains containing the type III antigen.

The cross-absorption tests in Table 1 show that the anti-MG serum used is an anti-III serum. This is in accordance with our general experience that streptococci carrying group and type antigens often give rise to antibodies against the type antigen only. From these data it can be concluded that Streptococcus MG (NCTC $8037 / 50$ ) is serologically identical with an F III strain.

Sixteen strains of the National Institute of Public Health (Utrecht) and 5 strains of the Institute for Dairying Hygiene (Kiel) which were classified as Streptococcus MG were tested in the capsular swelling test with anti-MG and anti-III sera. With formamide extracts of these strains capillary precipitin tests were made with all Lancefield group sera and with the type sera of group F. The correlation between capsular swelling and the precipitin reaction (Table 2) with anti-III serum is clear. Some strains gave a precipitin reaction with anti-F serum or with an anti-L serum (Burroughs Wellcome). In five strains no group antigen was detected. These 
strains were designated as 0 III (zero III). The strains which gave no positive capsular swelling reaction are probably not true MG strains.

Three out of the five 0 III strains in the first group gave big slimy colonies on $5 \%$ sucrose agar. They were therefore classified as Streptoccocus salivarius.

\begin{tabular}{|c|c|c|c|}
\hline \multirow{2}{*}{$\begin{array}{l}\text { Anti-MG serum } \\
\text { absorbed with } \\
\text { cells of }\end{array}$} & \multicolumn{3}{|c|}{ Formamide extract of } \\
\hline & C III & F III & MG \\
\hline C III & - & - & - \\
\hline F III & - & - & - \\
\hline MG & - & - & - \\
\hline $\mathbf{F}$ & + & + & + \\
\hline None & + & + & + \\
\hline
\end{tabular}

Table 2. Capsular swelling tests and precipitin reactions of strains classified as Streptococcus $M G$

\begin{tabular}{|c|c|c|c|c|c|}
\hline \multirow{2}{*}{$\begin{array}{l}\text { No. } \\
\text { of strains }\end{array}$} & \multicolumn{2}{|c|}{$\begin{array}{l}\text { Capsular swelling tests } \\
\text { with antiserum against }\end{array}$} & \multicolumn{3}{|c|}{$\begin{array}{l}\text { Precipitation reactions with } \\
\text { antiserum against }\end{array}$} \\
\hline & Type III & MG & Group L & Group F & Type III \\
\hline 8 & + & + & - & + & + \\
\hline $\mathbf{3}$ & + & + & + & - & + \\
\hline 5 & + & + & - & - & + \\
\hline 2 & + & + & - & + & + \\
\hline 1 & + & + & - & - & + \\
\hline 2 & - & - & - & - & - \\
\hline
\end{tabular}

The first group of strains was obtained from the National Institute for Public Health, Utrecht, Netherlands. The second group was obtained from the Institute for Dairying Hygiene, Kiel, Germany.

Streptococcus salivarius (NCTC 8606) and 25 out of 42 freshly isolated $S$. salivarius strains gave positive precipitin reactions with an anti-III serum. Antisera against salivarius NCTC 8606 and against one of the strains without type III antigen (strain 51) were prepared. The reactions of the formamide extracts of both 'salivarius' strains and an F III strain, with their respective antisera, are given in Table 3. It is clear that strain 51 contains an antigen different from type III antigen, whereas both antigens are present in strain 8606 . These data were confirmed with cross absorption tests.

Formamide extracts of 42 'salivarius' strains were tested with anti-III, anti-8606 and anti-51 sera (Table 4). All strains react with anti-8606 serum; 5 strains contain the III antigen, 12 strains the 51 antigen and 25 strains both antigens, like strain 8606.

Chemical composition of carbohydrates in formamide extracts. Qualitative chemical analysis of various strains (Table 5) showed that in both F III and MG (NCTC 8037/50) galactosamine which represents the F antigen (Michel \& Willers 1964) was the main hexosamine.

Glucosamine was present in low amounts in F III but not in MG. Glucose, galactose and rhamnose were found in large amounts in F III and MG strains. 
The right-hand part of Table 5 gives a comparison of the results of the qualitative composition of Streptococcus salivarius (NCTC 8606), S. salivarius 51 and an 0 III strain. All contain glucosamine, glucose, galactose and rhamnose; $S$. salivarius 51 contains in addition mannose.

Table 3. Cross-reactions and cross-absorptions of anti-salivarius NCTC 8606, anti-salivarius 51, and anti-III sera

\begin{tabular}{lcccc}
\multicolumn{1}{c}{ Serum } & $\begin{array}{c}\text { Absorbed } \\
\text { with }\end{array}$ & \multicolumn{3}{c}{ Formamide extract of } \\
\cline { 2 - 5 } Anti-sal 8606 &. & +++ & +++ & Sal 8606 \\
Anti-sal 51 & $\cdot$ & ++ & - & ++ \\
Anti-III &. & +++ & +++ & ++ \\
Anti-sal 8606 & Sal 51 & +++ & +++ & - \\
Anti-sal 8606 & F III & \pm & - & + \\
Anti-sal 51 & Sal 8606 & - & - & - \\
Anti-III & Sal 8606 & - & - & -
\end{tabular}

$+++=$ precipitation immediately positive; $++=$ precipitation positive in 30 sec.; $+=$ precipitation positive in $2 \mathrm{~min} . ; \pm=$ weak precipitation reaction within 5 min.; $-=$ no precipitation within 5 min.

Table 4. Reactions of salivarius strains with anti-salivarius and anti-III sera

$\begin{array}{cccc}\begin{array}{c}\text { Number of } \\ \text { isolated } \\ \text { strains }\end{array} & \begin{array}{c}\text { Anti-8606 } \\ \text { serum }\end{array} & \begin{array}{c}\text { Anti-51 } \\ \text { serum }\end{array} & \begin{array}{c}\text { Anti-III } \\ \text { serum }\end{array} \\ 25 & + & + & + \\ 12 & + & + & - \\ 5 & + & - & +\end{array}$

Table 5. Qualitative sugar composition of formamide extracts of Streptococcus $M G$, F III, O III and Streptococcus salivarius NOTO 8606 and strain 51

$\begin{array}{lccccc} & \text { MG } & & & \text { Salivarius } & \text { Salivarius } \\ \text { Galactosamine } & \text { NCTC 8037 } & \text { F III } & \text { 0 III } & \text { NCTC 8606 } & \mathbf{5 1} \\ \text { Glucosamine } & + & +++ & - & - & - \\ \text { Galactose } & - & + & + & + & + \\ \text { Glucose } & ++ & ++ & +++ & +++ & ++ \\ \text { Rhamnose } & +++ & +++ & +++ & +++ & +++ \\ \text { Mannose } & +++ & +++ & +++ & +++ & +++ \\ \text { N-Acetylhexosamine } & + & - & - & - & + \\ & \pm & ++ & + & ++ & ++\end{array}$

Inhibition of the quantitative precipitation. The results of the inhibition reactions by simple sugars of the III/anti-III and MG/anti-MG reaction are compared (Table 6). Only the sugars giving at least $30 \%$ inhibition are shown; for other sugars tested see Willers et al. (1964). In both systems the same sugars gave a measurable amount of inhibition at the sugar levels used. These results suggest that the determinant groups of the type III antigen have many properties in common with those of an antigen of Streptococcus MG. As mentioned before Streptococcus MG only gives rise to antibodies against the type III antigen. Therefore the inhibitions 
of the precipitin reaction of MG antigen and anti-F serum were studied. $50 \%$ inhibition was reached by $8 \mu \mathrm{M}$-cellobiose and by $0.01 \mu \mathrm{M}-3-0-\beta$-D-glucopyranosyl$N$-acetyl-D-galactosamine. As the latter is a disaccharide of the determinant group of the $\mathrm{F}$ antigen (Michel et al. 1964) the results of these inhibitions give further evidence for the presence of the $\mathbf{F}$ antigen in the formamide extracts of Streptococcus MG.

Table 6. Inhibition by simple sugars of precipitin reactions of the type III and the Ma systems

$\begin{array}{lcc} & \text { III/anti-III } & \text { MG/anti-MG } \\ \text { Glucose } & \mathbf{9 0 *} & \mathbf{4 2} \\ \beta \text {-Methylglucose } & \mathbf{4 6} & \mathbf{3 2} \\ \text { Cellobiose } & \mathbf{3 4} & \mathbf{2 6} \\ \text { Gentiobiose } & \mathbf{1 8} & \mathbf{1 8} \\ \alpha \text {-Methylglucose } & \mathbf{4 1} \dagger & \mathbf{5 5} \dagger \\ \text { Galactose } & \mathbf{9 0} & \mathbf{3 3} \\ \text { Melibiose } & \mathbf{6 0} & \mathbf{2 2} \dagger \\ \text { Glucosamine } & \cdot & \mathbf{3 7} \\ \text { Galactosamine } & - & \mathbf{4 8} \dagger \\ \text { * 50\% inhibition value expressed in } \mu \text { M-sugar. } \\ \dagger \mathbf{3 0} \% \text { value, where the 50\% value was not reached. }\end{array}$

Table 7. Inhibition by simple sugars of the precipitin reactions of the type III and both salivarius systems, the cross reacting systems of type III and salivarius NCTC 8606 and the system salivarius 8606 antigen/anti-salivarius 8606 adsorbed with salivarius 51 bacteria

\begin{tabular}{|c|c|c|c|c|c|c|}
\hline & $\underset{\text { anti-III }}{\text { III/ }}$ & $\begin{array}{c}8606 / \\
\text { anti-III }\end{array}$ & $\underset{\text { anti-8606 }}{\text { III }}$ & $\begin{array}{c}8606 / \\
\text { anti-8606 }\end{array}$ & $\begin{array}{c}8606 / \\
\text { anti-8606/ } \\
\text { absorbed with } \\
51 \text { bacteria }\end{array}$ & $\begin{array}{c}51 / \\
\text { anti-51 }\end{array}$ \\
\hline Glucose & $90 *$ & $\mathbf{3 0}$ & $88 \dagger$ & 44 & 59 & $\longrightarrow$ \\
\hline$\beta$-Methylglucoside & 46 & 14 & 14 & 7 & $\mathbf{5}$ & - \\
\hline Cellobiose & 34 & 8 & $48 \dagger$ & 30 & 55 & 一 \\
\hline Gentiobiose & 18 & 6 & 16 & $\mathbf{3}$ & $\mathbf{3}$ & - \\
\hline$\alpha$-Methlyglucoside & $41 \dagger$ & 82 & $110 \dagger$ & $\mathbf{8 2}$ & 96 & $110 \dagger$ \\
\hline Galactose & 90 & 15 & $\mathbf{5 9} \dagger$ & $\mathbf{3 0}$ & 44 & $103 \uparrow$ \\
\hline Melibiose & 60 & 7 & $44 \dagger$ & 37 & 60 & $60 \dagger$ \\
\hline Rhamnose & 一 & $114 \dagger$ & - & $137 \dagger$ & $130 \dagger$ & 113 \\
\hline Glucosamine & - & 100 & $40 \dagger$ & 62 & 87 & 100 \\
\hline Galactosamine & - & $50 \dagger$ & $74 \dagger$ & 100 & 99 & $62 \dagger$ \\
\hline
\end{tabular}

The inhibition reactions of the different 'salivarius' systems, the III system and an absorbed anti-salivarius 8608 /salivarius 8606 system were compared with each other ('Table 7). Except for the 'salivarius' 51 system, the same sugars as in the III/anti-III system were active. In the 'salivarius' 51 system rhamnose gave a weak inhibition reaction. Because anti-A variant serum is directed against rhamnose endgroups (McCarty 1956) this serum was tested against a formamide extract of $S$. salivarius 51 ; it was inactive. 


\section{DISCUSSION}

Soon after its discovery in 1943 Streptococcus MG was serologically examined and classified as a separate genus, which was only related to Streptococcus salivarius type I as described by Sherman et al. (1943). The precipitin reactions with formamide extracts, the cross-absorption tests and the inhibition of the quantitative precipitin reaction suggest that Streptococcus MG contains the same polysaccharide antigens as Streptococcus F III and can be classified as F III.

All strains containing the III antigen will react with an anti-MG serum. F III, L III and 0 III strains were positive (Table 2) and as the III antigen is also found in combination with the group antigen C (Ottens \& Winkler, 1962), these C III strains will also give positive reactions with anti-MG sera. Part of the strains classified as 0 III proved to be Streptococcus salivarius. The relationship between Streptococcus MG and Streptococcus salivarius type I of Sherman et al. (1943) as found by Mirick et al. $(1944 b)$ can be explained by the reactions of both with anti-III serum. A second unrelated 'salivarius' antigen (strain 51) was found. The relationship between strain $\mathbf{5 1}$ antigen and the 'salivarius' type II antigen of Sherman could not be investigated, as the latter strain was not available.

Qualitative chemical analysis and the inhibition of the precipitin reaction gave further confirmatory information about the identity of Streptococcus MG and F III strains.

Qualitative of chemical analysis of the hydrolysates of the formamide extracts Streptococcus salivarius and 0 III strains showed the same sugar composition. Strain 51 however contained in addition mannose. The difference between the 'salivarius' and 0 III strains on the one hand and MG and F III on the other is shown by the difference in the hexosamines found. In the first group of strains glucosaminine is found and galactosamine is lacking, whereas in the second group galactosamine is the main hexosamine. As has been shown earlier (Willers et al. 1964) galactosamine is the main hexosamine in the group $\mathbf{F}$ antigen. The inhibition of the precipitin reactions of the 'salivarius' and III systems (Table 7) are very similar. In both a $\beta$-glucosidic and a galactosidic group seem to act as a determinant of the antigens. Whenever anti-III serum is used cellobiose gives a better inhibition than $\beta$-methylglucoside and almost equals that given by gentiobiose. When, however, anti-salivarius 8606 serum is used the inhibiting capacity of $\beta$-methylglucoside and gentiobiose are the same and exceed that of celliobiose. From these differences it can be seen that anti-salivarius 8606 serum contains antibodies with combining sites that fit better with $1 \rightarrow 6$ - $\beta$-glucosidic linkage than with a $1 \rightarrow 4$ - $\beta$-glucosidic linkage. Although the type III and salivarius 8606 systems give strong cross reactions, these results suggest that the determinant groups of the antigens are not completely identical. A more detailed study with oligosaccharides obtained by partial hydrolysis of the antigens will be necessary to study possible differences between the determinant groups of the type III and salivarius 8606 antigens.

The inhibition pattern of strain 51 indicates a different antigenic structure. Only rhamnose gives a slight inhibition, a reaction found in the A variant (McCarty, 1956), C variant (Krause \& McCarty, 1963) and group G (Curtis \& Krause, 1964) systems. 
No relationship between the variant A system and the 'salivarius' type 51 system was found.

The inhibition given by the hexosamines in several systems, in which the $N$-acetyl hexosamines were inactive is not quite clear. Good inhibitions given by arginine and lysine in the same systems suggest that anti-protein reactions are involved here.

This is the third paper of a series of 'Immunochemistry of group F streptococci'. The authors are indebted to Professor Dr K. C. Winkler for constant advice and to Dr C. E. de Moor for suggesting a relationship between the antigens of Streptococcus MG and the group and type antigens of group F. The skilful technical assistance of Miss M. J. Sijsma and Miss T. Alderkamp is gratefully acknowledged.

Part of the work has been supported financially by the Netherlands Organization for the Advancement of Pure Research (Z.W.O.).

\section{REFERENCES}

McCARTY, M. (1956). Variation in the group specific carbohydrate of group A streptococci. II. Studies on the chemical basis for serological specificity of the carbohydrates. J. exp. Med. 104, 629.

Curtis, S. N. \& Krause, R. M. (1964). Immunochemical studies on the specific carbohydrate of group G streptococci. J. exp. Med. 119, 997.

KraUSe, R. M. \& McCarty, M. (1962). Variation in the group specific carbohydrate of group $\mathrm{C}$ hemolytic streptococci. J. exp. Med. 116, 131.

MrCheL, M. F. \& Gooder, H. (1962). Amino acids, amino sugars and sugars present in the cell wall of some strains of Streptococcus pyogenes. J. gen. Microbiol. 29, 199.

Mrchel, M. F. \& Willers, J. M. N. (1964). Immunochemistry of group F streptococci. Isolation of group specific oligosaccharides. J. gen. Microbiol. 37, 381.

Mirick, G. S., Thomas, L., Curnen, E. C. \& Horsfall jun., F. L. (1944). Studies on a non-hemolytic streptococcus isolated from the respiratory tract of human beings. I. Biological characteristics of Streptococcus мG. J. exp. Med. 80, 391.

Mrrick, G. S., Thomas, L., Curnen, E. C. \& Horsfall jun., F. L. (1944 a). Studies on a non-hemolytic streptococcus isolated from the respiratory tract of human beings. II. Immunological characteristics of Streptococcus MG. J. exp. Med. 80, 407.

Mirick, G. S., Thomas, L., Curnen, E. C. \& Horsfall jun., F. L. (1944 $b$ ). Studies on a non-hemolytic streptococcus isolated from the respiratory tract of human beings. III. Immunological relationship of Streptococcus MG to Streptococcus salivarius type I. J. exp. Med. 80, 431.

Ottens, H. \& Winklen, K. C. (1962). Indifferent and hemolytic streptococci possessing group antigen F. J. gen. Microbiol. 28, 181.

Sherman, J. M., Niven jun., C. F. \& Smirey, K. L. (1943). Streptococcus salivarius and other non-hemolytic streptococci of the human throat. J. Bact. 45, 249.

Willers, J. M. N., Michel, M. F., Sysma, M. J. \& Winkler, K. C. (1964). Chemical analysis and inhibition reactions of the group and type antigens of group $F$ streptococci. J. gen. Microbiol. 36, 95. 